\title{
GAS CHROMATOGRAPHIC - MASS SPECTROMETRIC METHODS FOR THE DETECTION AND IDENTIFICATION OF ANABOLIC STEROID DRUGS
}

\author{
Roberta J. WARD, C. H. L. SHACKLETON and A. M. LAWSON \\ Division of Clinical Chemistry, Clinical Research Centre (Northwick Park Hospital) \\ Watford Road, Harrow, Middlesex, HA1 3UJ
}

\section{INTRODUCTION}

Methods for the detection of certain anabolic steroid drugs and their metabolites by radioimmunoassay have been developed by Professor R. V. Brooks and his associates during the last few years (Sumner, 1974).

Recently we have been examining the alternative analytical procedure of gas chromatography-mass spectrometry for the detection and identification of anabolic steroid drugs and their urinary metabolites.

Our three main objectives in this study were:-

1. To characterise the major urinary metabolites of a number of anabolic steroid drugs.

2. To identify unequivocally drugs or their metabolites in urine samples obtained from athletes where radioimmunoassay had given positive results.

3. To develop procedures for the positive identification of drugs or drug metabolites for which radioimmunoassays do not yet exist.

\section{EXPERIMENTAL}

\section{Collection of urine samples}

Investigation of metabolism of anabolic steroids: A control sample was collected prior to administration of 10 or $20 \mathrm{mg}$ of the drug under investigation. ${ }^{*}$ Thereafter urine was collected for the first $\mathbf{4 8}$ hours and then one sample each day for 7 days.

Identification of anabolic steroids in urine from athletes: Urine samples were collected from athletes attending the 1974 Commonwealth Games in Christchurch and the European Games held in Rome, 1974. These specimens were analysed initially by Professor Brooks using radioimmunoassays and then submitted to us for independent assessment.

\section{Steroid extraction and fractionation}

The urine specimens were poured on to columns of Amberlite XAD-2 resin to extract free and conjugated

\footnotetext{
*Permission to carry out these drug studies was granted by the Northwick Park Hospital Ethical Committee.
}

steroids. The columns were washed with water and the steroids recovered by elution with ethanol. The ethanol was taken to dryness and the residue dissolved in $0.5 \mathrm{M}$ acetate buffer ( $\mathrm{pH} \mathrm{4.6)}$ and the steroid conjugates were hydrolysed by two enzymes present in snail digestive juice (Helix pomatia) and $\beta$-glucuronidase. After 48 hours the free steroids were extracted on XAD-2 columns and eluted with ethanol.

It was found desirable to fractionate the steroid extracts prior to gas chromatographic analysis to increase the sensitivity of the method by removing some of the normal endogenous steroid metabolites. $6 g$ Sephadex LH-20 columns were used with the solvent system cyclohexane: ethanol 4:1 (Setchell and Shackleton, 1973), and $10 \mathrm{ml}$ fractions were collected and taken to dryness.

\section{Derivitisation}

Trimethylsilyethers were prepared of the steroid fractions by dissolution in dry pyridine $(200 \mu \mathrm{l})$ and treatment with $200 \mu l$ of hexamethyldisilazane and $50 \mu$ of trimethylchlorosilane. The reaction was allowed to proceed overnight at room temperature and the reagents were removed under a stream of nitrogen. The residue was taken up in cyclohexane.

\section{Gas chromatography-mass spectrometry}

Preliminary gas chromatographic analysis was carried out on a Pye 104 instrument using a $3 \%$ OV -1 column with temperature programming from 200 to $270^{\circ}$ at $2^{\circ}$ per min. The mass spectrometer used was a Varian Mat 731 instrument and data acquired and processed by a Varian 100 MS SpectroSystem. The mass spectrometer was used in three different modes:

1. Conventional individual scans taken of gas chromatographic peaks. This scanning was under the control of the operator.

2. Repetitive scans where the instrument automatically takes a scan every 8 seconds during the period of elution of the sample from the gas chromatograph. From the data obtained changes in the intensities of selected ions characteristic of the compound under investigation could be plotted against mass spectrum scan number by the computer.

3. Selected ion monitoring where the mass spectrometer has been set to monitor the intensity of only a 
few individual ions which are characteristic of the drug metabolites. This technique does not require the use of the data system.

\section{RESULTS AND DISCUSSION}

We restricted our study of anabolic steroid metabolism to those compounds illustrated in Fig. 1. Their metabolism and detection will be described in each compound in the following sections.

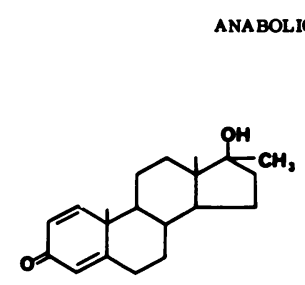

17a-methyl-1, 4-androstadien 17\%-ol-3-one (Dianabol)

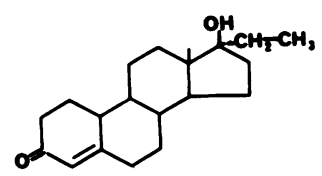

$17 \alpha-E$ thyl -4 -estren $-17 \beta-o l-o n e$ (Nilevar)
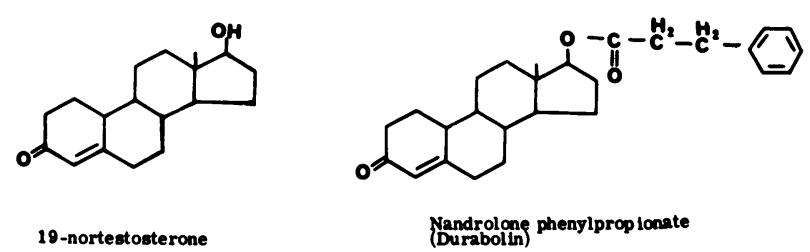

19-nortestosterone

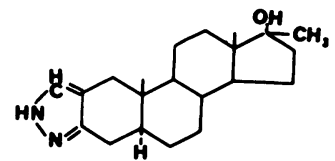

$17 \alpha$-methyl-5 $\alpha$-androstan $17 \beta$ of $-(3 ., 2-C)-$ py razole (Stromba)

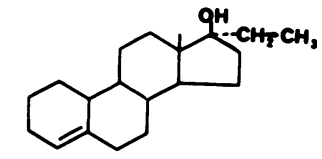

$17 \alpha-$ Ethyl -4 -estren $-17 \beta-$ ol (Orabolin)

(Durabolin)

Figure 1. Structure and systematic names of the anabolic steroid drugs studied in this investigation.

\section{Dianabol}

The mass spectra of the silyl ethers of Dianabol and its major urinary metabolite, 6 $\beta$-hydroxy-Dianabol (Rongone, 1963), are shown in Fig. 2. The principal fragmentation is across the D-ring giving rise to a peak at $\mathrm{m} / \mathrm{e}$ 143. This ion is present in metabolites of Dianabol (Lawson, 1971) and in other anabolic steroids with the same D-ring substitution. Although $\mathrm{m} / \mathrm{e} 143$ is a characteristic ion in these cases it is not unique and arises from different sources in several endogenous steroids. However, if $\mathrm{m} / \mathrm{e} 143$ is monitored while a derivatised urine sample, containing 63-hydroxy-Dianabol, is eluting from

the gas chromatograph into the mass spectrometer, a response at the gas chromatographic retention time of 3 $6 \beta$-hydroxy-Dianabol is sufficiently specific to identify its presence (Lawson, 1971). The specificity is improved by monitoring a characteristic ion of 63-hydroxy-Dianabol but a less common fragment ion in endogenous? steroids, e.g. $\mathrm{m} / \mathrm{e} 209$, or by following several ions, e.g. $\mathrm{m} / \mathrm{e} 143,209,281$ and 357.
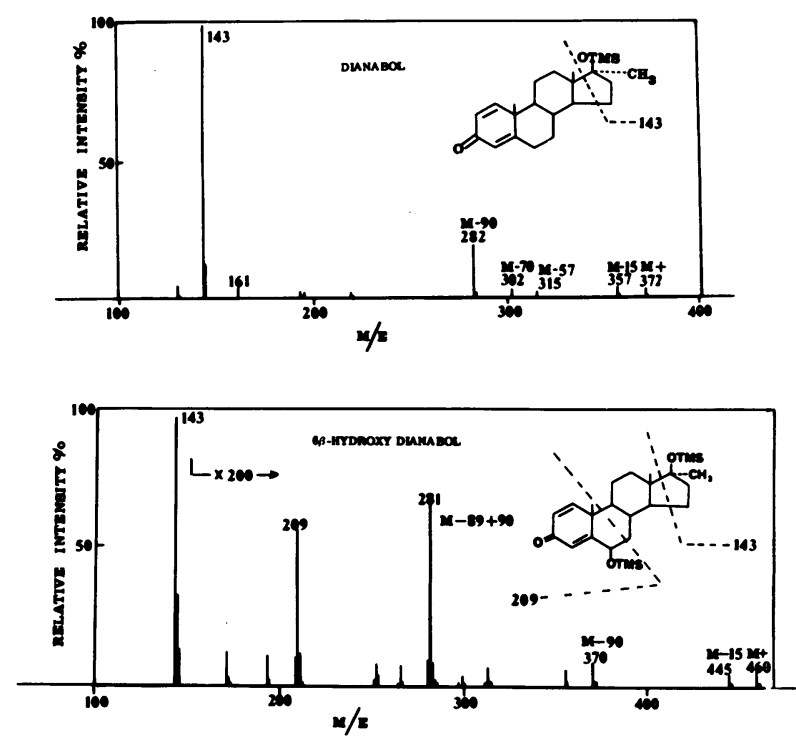

Figure 2. Mass spectra and fragmentation of the trimethy/silyl ethers of Dianabol and its principal urinary metabolite $6 \beta$ hydroxy-Dianabol.

The screening method we adopted to detect the 3 presence of 63-hydroxy-Dianabol in urine samples from athletes comprised an initial fractionation stage using Sephadex LH-20 followed by trimethylsilylation and $\delta$ then selected ion monitoring of $\mathrm{m} / \mathrm{e} 209$. The chromotograms from these, together with undrugged urine control 윽 samples are shown in Fig. 3. The two controls show no evidence of a m/e 209 peak while two of the athlete samples have response peaks with the correct retention $N$ time for $6 \beta$-hydroxy-Dianabol. This was good evidence that Dianabol had been taken by these two athletes. Full $\tilde{N}$ mass spectral scans of the region in question provided $\underset{\mathrm{W}}{\mathrm{W}}$ complete confirmation of the presence of $6 \beta$-hydroxyDianabol by comparison with an authentic reference 0 mass spectrum. Later we learned that these two samples $\underset{\mathbb{D}}{\overparen{D}}$ had given a positive response to the radioimmunoassay $\stackrel{\oplus}{+}$ for a 17-hydroxy-17-methyl steroid.

We investigated these samples further using the repeti- $\stackrel{\AA}{\circledR}$ tive scanning technique. Although this is less sensitive $\stackrel{\mathbb{Q}}{\mathbb{Q}}$ than selected ion monitoring, by one to two orders of magnitude, it does have several advantages. These are

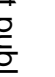

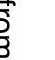


that complete spectra are available for all gas chromatographic peaks, no preselection of ions is necessary and selected ions for any drug metabolite can be searched for in the acquired data.

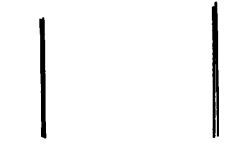

Single ion monitoring $\mathrm{m} / \mathrm{e} 209$
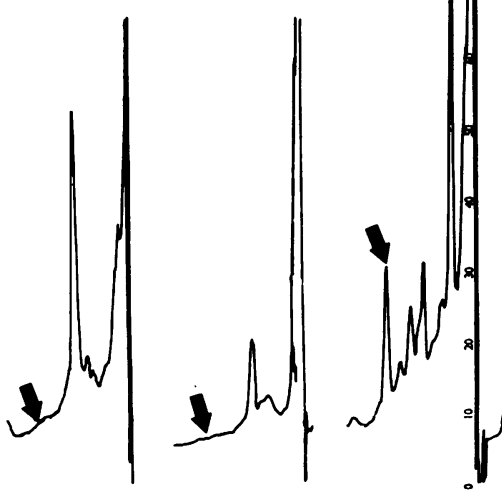

Figure 3. Detection of the trimethy/silyl ether of $6 \beta$-hydroxyDianabol by selective ion monitoring of the fragment $\mathrm{m} / \mathrm{e}$ 209. The two chromatograms on the left are controls and those on the right represent samples obtained from two athletes attending the Commonwealth Games. The major peak had the gas chromatographic retention time of $6 \beta$-hydroxy-Dianabol thus confirming its presence.

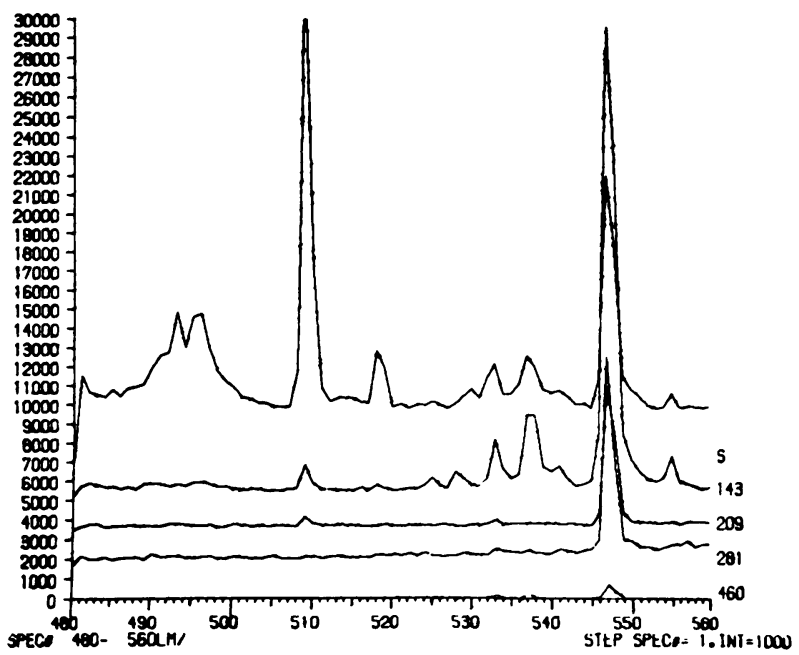

Figure 4. Data retrieval following repetitive scanning. The ions chosen are listed on the right hand side, their intensities on the left and scan number along the bottom. The upper chromatogram (S) represents the total-ion-current recording.
From the repetitive scanning data, acquired from the two positive Commonwealth Games samples, ions $\mathrm{m} / \mathrm{e}$ $143,209,281$ and 460 were plotted against scan number (Fig. 4) and the expected confirmatory responses obtained for 63-hydroxy-Dianabol at the correct retention time. The main point to be made is that this data could be searched for any of the characteristic ions listed in Table $I$ and the identity be obtained rapidly of the specific drug ingested. Alternatively it would be possible to identify drug or drug metabolite peaks automatically using a computer held library of reference spectra.

\begin{tabular}{|c|c|c|}
\hline DRUG & MUOR URDNARY PROOUCTS & MUOR IONS FOR DETECTION \\
\hline DINABOC & Unchanged & $130,143,282,372$ \\
\hline $\begin{array}{l}\text { 17 } 7 \text {-Hydroxy-17a-methyl- } \\
\text { androsta } 1,4 \text { dien-3-one }\end{array}$ & $6 \beta$-Hydroxy-D1anabol & $143,209,281,460$ \\
\hline STROAEA & Unchanged & $94,96,143,258,310,330,385,400$ \\
\hline $\begin{array}{l}\text { 17 } 7 \text {-Hydroxy-17a-methyl- } \\
5 \alpha \text {-androstane }(3,2 c) \\
\text { pyrazole }\end{array}$ & - & $94,96,143$ \\
\hline$\underline{\text { NIEEVAR }}$ & Unchanged & $144,157,255,303,345,374$ \\
\hline 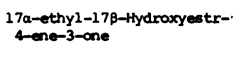 & $\begin{array}{l}\text {-Tetra hydro } \\
-2 \mathrm{OH}+\mathrm{H}_{4}\end{array}$ & $\begin{array}{l}144,157,241,331,360,421,450 \\
241,245,331,421,538\end{array}$ \\
\hline ORABOCDN & Unchanged & $144,157,241,270,360$ \\
\hline $\begin{array}{l}17 \alpha-\text { ethylestr-4-ene- } \\
17 \beta \rightarrow 01\end{array}$ & $\begin{array}{l}-3-0 \times 00 \text { (Nilevar) } \\
-20 \mathrm{H}+\mathrm{H}_{4}\end{array}$ & $\begin{array}{l}144,157,255,303,345,374 \\
241,245,331,421,538\end{array}$ \\
\hline 19-nor - testosterone & $\begin{array}{l}\text { Unchanged } \\
\text {-nor-etiocholanolone } \\
\text { - Nor-androsterane }\end{array}$ & $\begin{array}{l}129,160,215,256,331,346 \\
129,239,257,258,333,348\end{array}$ \\
\hline DURABOLIN & Unchanged & - \\
\hline $\begin{array}{l}\text { 19-nor-testosterone } \\
\text { phenyl-proplonate }\end{array}$ & $\begin{array}{l}\text { nor-atiochalanolone } \\
\text { por-androstarcone }\end{array}$ & $129,239,257,258,333,348$ \\
\hline
\end{tabular}

We investigated the remaining drugs, Stromba, Orabolin, Nilevar and Durabolin (Fig. 1) to determine their major metabolites to enable us to choose the most suitable ions for their specific detection in screening methods for the future.

\section{Stromba}

Fig. 5 illustrates the mass spectrum of the trimethylsilyl derivatives of Stromba. As in Dianabol, the base peak is at $\mathrm{m} / \mathrm{e} 143$, formed from D-ring cleavage. Other signifi-

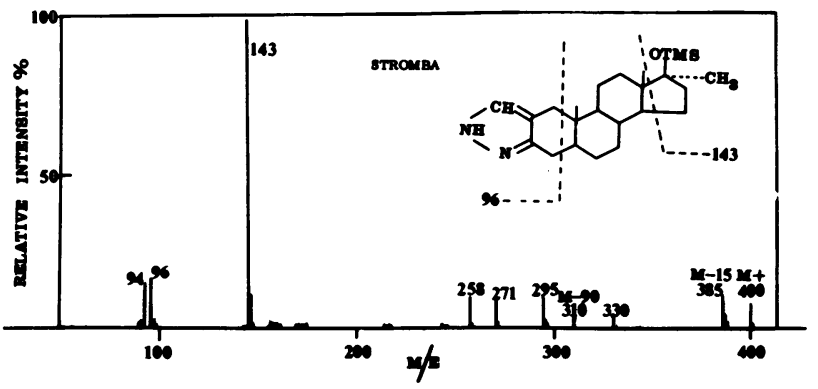

Figure 5. The mass spectrum and fragmentation of the trimethy/silyl derivative of Stromba. 
cant fragments are those at $\mathrm{m} / \mathrm{e} 94$ and 96 formed by A-ring fragmentation.

Unfortunately difficulty has been found in detecting Stromba or its urinary metabolites following administration of the drug. In addition the trimethylsilyl ether of Stromba has poor gas chromatographic properties due to the polarity of the pyrazole ring. Further investigation of the metabolism of this drug is in progress by administering high doses of Stromba to a primate species (Callithrix jacchus). Normally this monkey has a low steroid excretion, so any Stromba metabolites should be more apparent and these may be later sought in human urine.

\section{Durabolin}

Since the ester group of Durabolin is rapidly removed in the body to form 19-nor-testosterone the same methods are applicable for the analysis of both anabolic steroids. Although small amounts of 19-nor-testosterone were identified in urine following administration of Durabolin, the major metabolite was found to give a mass spectrum suggesting the structure 19-nor-aetiocholanolone or 19-nor-androsterone. Miedema et al. (1972), Dimick (1961) and Engel (1958) also report the conversion of 19-nor-testosterone to these 17-oxo-steroids and report a small increase in the excretion of oestrogens. However, in our study we were unable to detect either oestrone or oestradiol in the urine samples.

The major fragmentation ions of the silyl ether of the 19-nor-17-oxo-steroid were at $\mathrm{m} / \mathrm{e} 257$ and m/e 258 (M-90). Although these ions are also given by endogenous androsterone and aetiocholanolone the 19-nor-testosterone metabolite may be distinguished by its shorter retention time on gas chromatographic analysis. It was found that multiple ion detection of $\mathrm{m} / \mathrm{e}$ $257,258,333$ and 348 together with retention time data gives a specific determination of the 19-nor-testosterone metabolite. It was of interest that the metabolite could

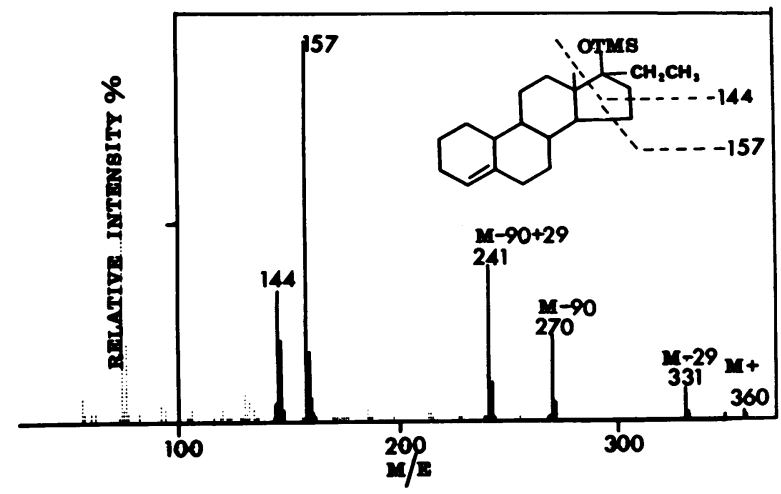

Figure 6. The mass spectrum of the trimethylsilyl ether of Orabolin. still be detected in urine 8 days after administration of the drug.

\section{Orabolin}

The equivalent ion in the spectrum of Orabolin-trimethylislyl ether (Fig. 6) to the m/e 143 in Dianabol-trimethylsilylether, occurs at $\mathrm{m} / \mathrm{e} 157$. Initially this was used, together with $\mathrm{m} / \mathrm{e} 144$, to detect any urinary metabolites with an unchanged D-ring. Several hydroxylated metabolites were observed in this way and partially of characterised from their mass spectra. However, the $\vec{\circ}$ major metabolite peak did not have the $\mathrm{m} / \mathrm{e} 157$ and 144 ions and instead showed ions $\mathrm{m} / \mathrm{e} 245$ and 231. This indicated a modified D-ring with the fragmentation shown in Fig. 7 demonstrating this to be 21-hydroxylation. Similar hydroxylation of the alkyl side-chain has also been reported for allylestrenol and Nilevar (Thyssen, 1967; Brooks et al., 1971).

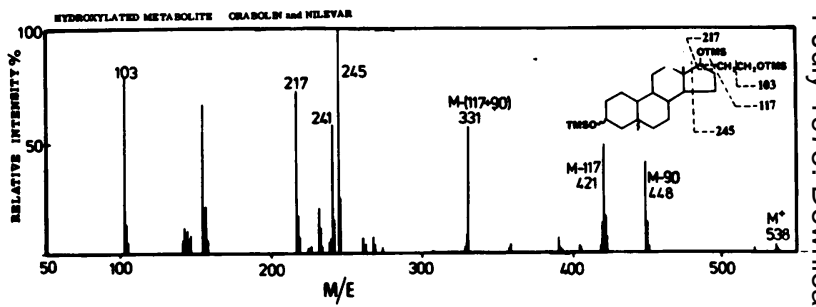

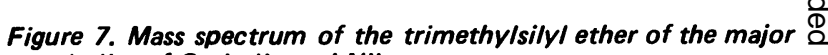
metabolite of Orabolin and Nilevar.

Another anabolic steroid, Nilevar was also shown to be an important metabolite of Orabolin and the 21-hydroxylated metabolite of Orabolin was also obtained in urine following ingestion of Nilevar. The proposed conversion of Orabolin and Nilevar to the major metabolite is illustrated in Fig. 8. This metabolite can be conveniently detected by repetitive scanning GC-MS and selecting the ions $\mathrm{m} / \mathrm{e} 421,331,241$ and 245.

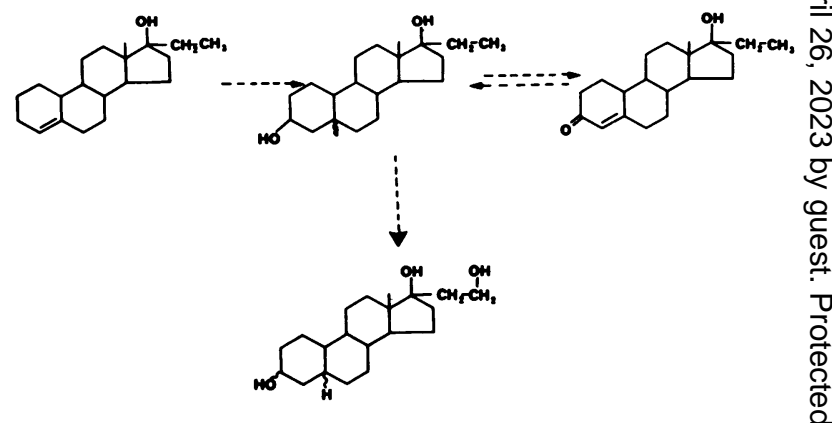

Figure 8. Proposed conversion of Orabolin (left) to Nilevar (right) and their common metabolite identified as a 19-nor-pregnanetriol. 


\section{Nilevar}

The metabolism of Nilevar has been investigated previously by GC-MS using single ion monitoring by Brooks and co-workers (1971). In the present study a number of metabolites were found with the principal one being the 19-nor-pregnanetriol identified as the major metabolite of Orabolin.

\section{CONCLUSIONS}

Table 1 summarises some of the data we have obtained so far. It lists the anabolic steroid drugs studied, the metabolites that have been identified or partially characterised and the principal ions which may be used for their specific detection by selective ion monitoring.

Although our studies of the metabolism of anabolic steroids are incomplete at present, we have shown that for most compounds it is possible to detect their metabolites in urine. We have demonstrated that 63-hydroxy-Dianabol can be detected in the small amount of urine obtained from athletes attending sporting events and there is no reason why metabolites of other steroid drugs should not be detected in an analogous fashion. The principal disadvantage in gas chromatography-mass spectrometry is the length of time required for each analysis. Radioimmunoassay is more suitable for screening purposes and in an ideal situation initial investigations would be carried out by this technique. Mass spectrometry could then be used to identify positively the drug being taken. However, radioimmunoassays do not yet exist for all anabolic steroids or their metabolites and until this situation is rectified mass spectrometry may be the only means of detecting certain drugs.

\section{ACKNOWLEDGEMENTS}

This work was supported by a grant from the Sports Council. We are also indebted to the MRC for allowing their facilities at the Clinical Research Centre to be used for this study.

The authors wish to thank Mr. M. Chu and Mr. M. Madigan for technical assistance with the mass spectrometry. The anabolic steroid drugs used in this study were donated by Ciba, G. D. Searle and Organon Laboratories Ltd.

R. J. Ward wishes to acknowledge that results of the research work reported in the communication may be incorporated in a thesis for a Council of National Academic Awards Degree.

\section{REFERENCES}

Audier, H.-E., Bottin, J., Fetizon, M. and Gramain, J. C. 1971 Orientation de la fragmentation en spectrometrie de masse par introduction de groupements fonctionnels. X. Pyrazoles derives de ceto-3-steroids. Bulletin de la Societe Chimique de France, No. 11, 4027-4032.

Both-Miedema, R., Van Groenestein, T. J. A., de Groot, W. C., Huis In't Veld, L. G., Rijsdijk, J. C. J. M. and Stekelenburg, P. 1972. 19-Nortestosterone. I. Its metabolism in the rabbit. Steroid Lipid Research, 3 49-58.

Brooks, C. J. W., Thawley, A. R., Rocher, P., Middleditch, B. S., Anthony, G. M. and Stillwell, W. G. 1971. Characterization of steroidal drug metabolites by combined gas chromatography-mass spectrometry. Journal of Chromatographic Science, 9, 35-43.

Dimick, D. F., Heron, M., Baulieu, E.-E. and Jayle, M.-F. 1961. A comparative study of the metabolic fate of testosterone, $17 \alpha$-methyl-testosterone, 19-nortestosterone, 17 $\alpha$-methyl-19-nortestosterone and 17 $\alpha$-methyl-estr-5(10)ene-17ß-ol-3-one in normal males. Clinica Chimica Acta, 6, 63-71.

Engel, L. L., Alexander, J. and Wheeler, M. 1958. Urinary metabolites of administered 19-nortestosterone. Journal of Biological Chemistry, 231, 159.

Lawson, A. M. and Brooks, C. J. W. 1971. A sensitive method for the detection of metabolites of Dianabol in urine in man. Biochemical Journal, 4, 25P.

Rongone, E. L. and Segaloff, A 1963. In vivo metabolism of $\Delta^{\prime} 17 \alpha$-methyltestosterone in man. Steroids, 1, 179.

Setchell, K. D. R. and Shackleton, C. H. L. 1973. The group separation of plasma urinary steroids by chromatography on Sephadex LH-20. Clinica Chimica Acta, 47, 381-388.

Sumner, N. A. 1974. Measurement of anabolic steroid by radioimmunoassay. Journal of Steroid Biochemistry, 5, 307.

Thyssen, J. H. 1967. Thesis to the University of Utrecht. 